\title{
Saliendo al encuentro. Una aproximación relacional a la experiencia intersubjetiva con los niños con autismo ${ }^{1}$
}

\author{
Brianda Portalatín ${ }^{2}$ \\ Londres, Reino Unido
}

\begin{abstract}
Aproximándonos al autismo desde una perspectiva psicoanalítica contemporánea, lo entendemos como una experiencia que es vivida, cuya dificultad nuclear reside en el dominio sensorio-motriz y en la disminuida experiencia de relación intersubjetiva. Tal comprensión nos permite ofrecer un tratamiento enfocado en la mejora de la relación intersubjetiva.
\end{abstract}

Palabras clave: Autismo, relación intersubjetiva.

Approaching autism from a contemporary psychoanalytic point of view, we understand it as an experience that is lived, whose core difficulty lies in the sensory-motor domain and in the diminished experience of intersubjective relationship. Such understanding allows us to offer a treatment focused on improving the intersubjective relationship.

Key Words: Autism, intersubjective relationship.

English Title: Approaching the meeting. A relational approach to the intersubjective experience with children with autism.

\section{Cita bibliográfica / Reference citation:}

Portalatín, B. (2020). Saliendo al encuentro. Una aproximación relacional a la experiencia intersubjetiva con los niños con autismo. Clínica e Investigación Relacional, 14 (2): 400-411. [ISSN 1988-2939] [Recuperado de www.ceir.info ] DOI: 10.21110/19882939.2020.140208

\footnotetext{
${ }^{1}$ Este trabajo mereció el primer premio del Certamen "Devenir Psicoterapeuta" convocado por el Instituto de Psicoterapia Relacional, en su edición de 2019.

2 Psicóloga General Sanitaria y Psicoterapeuta Psicodinámica Relacional.

E-mail: Brianda.portalatin@gmail.com
}

CeIR Vol. 14 (2) - Octubre 2020 ISSN 1988-2939 - www.ceir.info

(c) Derechos reservados/Copyright de Clínica e investigación Relacional y los autores. Prohibida la reproducción total o parcial sin autorización expresa. Este material es para uso científico y profesional exclusivamente y puede contener información clínica sensible. Los editores no se responsabilizan de los contenidos de los autores. Dirigir las consultas sobre derechos y autorizaciones a ceir@psicoterapiarelacional.es 


\section{Introducción}

El autismo, entendido desde una perspectiva psicoanalítica contemporánea, es una experiencia que es vivida, una condición fenomenológica cuya dificultad nuclear reside en el dominio sensorio-motriz y en la disminuida experiencia de relación intersubjetiva (Emanuel, 2015). Comprenderlo así nos permite ofrecer un tratamiento que procura mejorar el desarrollo de la relación intersubjetiva.

Esta comprensión se aleja de la más prevaleciente, por lo general concordante con el modelo médico, que presenta el autismo como algo concreto que "alguien tiene" y caracterizado por un conjunto de comportamientos descontextualizados.

Dado que este trabajo surge como una invitación a profundizar en el pensamiento relacional y a reflexionar sobre nuestro propio devenir psicoterapeutas, procuraremos abordar en él la experiencia de encuentro con niños con autismo.

Con el fin de comprender la condición del niño con autismo, procuramos apresarla con palabras muy finamente calibradas. Sin embargo, a pesar del gigantesco esfuerzo de ajuste que hacemos, las palabras no terminan de permitirnos asir tal experiencia por completo 3 . Sabiéndonos limitados de base, lo hacemos lo mejor posible y tal vez esta pueda ser una de las razones por las que con frecuencia utilizamos las metáforas para tratar de esclarecer el autismo. Las metáforas nos permiten el acceso a un campo distinto del lógico-simbólicoverbal, más cercano a ese otro que pretendemos alcanzar.

Lo que nos ayuda a pensar el autismo es estar cerca de la experiencia de los individuos con esta condición (Emanuel, 2015. Durban, 2014. Tustin, 1990), sumergirnos con el niño en esa experiencia única que es la suya.

Cristina Emanuel (2015) nos indica que el autismo es la excepción que confirma la regla de que nuestras mentes se construyen interpersonal e intersubjetivamente. Aunque verdaderamente no sabemos si sea realmente una excepción o una poderosa confirmación de lo inextricablemente unidos que se encuentran el infante y el cuidado materno en las primeras etapas de la vida (Winnicott, 1965). Desconocemos "cuánto" sentimiento de vacuidad puede albergar "una mente común", pero intuimos que menos del que hospedan en sus entrañas estos niños.

\footnotetext{
${ }^{3}$ Compartiendo su trabajo, muchos autores nos presenta viñetas clínicas increíblemente ilustrativas. Varios de ellos, viendo más allá de las palabras, nos permiten intuir lo verdaderamente crudo y debilitador de la forma de experienciar de estos niños. Sin embargo, la experiencia no deja de estar mediada por su narración y por muy empáticos que seamos y más fantástica que sea la sensibilidad del autor, hay algo imposible de apresar, de reflejar, de transmitir. Algo que se queda en un plano al que no alcanza nuestra forma de comunicación verbal.
} 


\section{¿El sentido de sí?}

Las actividades que llevan a cabo estos niños no les ayudan a desarrollar un sentido de sí, sino una envoltura protectora. Tales actividades, además, no sustituyen, sino que reemplazan al otro y bloquean la toma de conciencia de éste. Permaneciendo así congelados en un estado de indiferenciación con el mundo (Tustin, 1990).

Para experimentar la subjetividad propia, necesitamos reconocer al otro como un sujeto separado. Ésta interesante paradoja de Jessica Benjamin (1990. Como se cita en Emanuel, 2015) nos invita a cuestionarnos cuánta "mente" hay en un "¿sujeto?" indiferenciado... ¿Hay acaso un sujeto?

\section{Subjetividad encarnada}

Uno de los fenómenos distintivos de la experiencia del niño con autismo es lo que hemos venido a denominar el quiebro que sufre la encarnación de la propia subjetividad (aspecto encadenado a la cualidad de la relación intersubjetiva de que son capaces).

Comenzábamos señalando que una de las dificultades nucleares de estos niños se encuentra en su dominio sensorio-motor. Somos humanos sostenidos4 ${ }^{4}$-primeramente en un útero y posteriormente por unos brazos (Winnicott, 1965)- y "contenidos" en un cuerpo que percibe y siente. Estamos enraizados en él (en términos winnicottianos, somos una unidad psique-soma) y no hay forma de escapar a esto. Nuestro cuerpo nos informa de (y da forma al) mundo que nos rodea. A grandes rasgos podríamos decir que esto es a lo que nos referimos cuando hablamos de la subjetividad corporalizada. Poniendo la idea en palabras de expertos: Todo aquello que sabemos se asienta en nuestra interacción sensorio-motriz con el mundo (Lakoff y Johnson, 1999. Como se cita en Emanuel, 2015).

Nuestra comprensión de conceptos abstractos basada en concepciones sensoriales da buena cuenta de ello (Por ejemplo, para describir el afecto utilizamos conceptos sensoriales como calidez y cercanía). Sin metáforas, continúan estos mismos expertos, no nos es posible inferir significado, transmitir ideas ni tomar conciencia de nuestra propia subjetividad. Podríamos decir que la metáfora es el átomo de nuestra mente. Las dificultades con las metáforas, las abstracciones y la concepción de la subjetividad humana que encontramos en el autismo son consecuencias de las deficiencias sensorio-motrices de

\footnotetext{
4 Cuando observamos a "una madre" que sostiene entre sus brazos al bebé, no solo metafóricamente, sino sosteniéndolo de manera concreta (físicamente) estamos presenciando una forma de amar (Winnicott, 1965).
} 
esta población (Lakoff y Johnson, 1999. Como se cita en Emanuel, 2015), y debido a estas se ven limitados en el plano de la subjetividad.

\section{¿Y la vinculación?}

Somos seres "irreductiblemente corporales" y vinculares. A pesar de que la experiencia de cada uno es personal y única, la única forma que tenemos de hacernos con ella es a través del otro, gracias a la interacción sensorio-motora prereflexiva que tiene lugar en la díada. Cuando experimentamos la conexión afectiva y la resonancia a través de los sistemas sensoriales la experiencia se hace significativa y nos permite sentirnos reales y vivos (Coburn, 2001. Como se cita en Emanuel, 2015. Winnicott 1971).

Los niños en los que aquí nos centramos difícilmente encuentran confiable la intersubjetividad ya que, debido a sus dificultades de base (en cuanto a su particular procesamiento sensorial), cabe sospechar que no hubo suficiente registro de la experiencia sensoriomotora inicial que refleja la sintonización afectiva y como resultado:

a) Fallan en "sentirse como un sujeto" real.

b) Pierden la oportunidad de resonar con el otro.

Emanuel (2015) señala que el roto en la intersubjetividad típico de los sujetos con autismo está relacionado con la dificultad que tienen para 1) encontrar confiable el campo interpersonal y por tanto a) conseguir intimidad y b) reconocerse tanto a sí mismos como a los otros como Sujetos.

El desarrollo de la intersubjetividad es vital para el individuo, nos es imposible vivir fuera de la matriz relacional en la que estamos inmersos. Al observarlos, si describimos la conducta observable, vemos que estos niños quedan aislados, pero esto sucede así por la incapacidad que venimos describiendo, no es una decisión voluntaria, y a pesar de ello, la necesidad psíquica de entrelazarnos subjetivamente permanece. Señalaba Winnicott (1971) que para la mayor parte de las personas, el mayor elogio es ser descubierto y utilizado. Como cualquier otro individuo, el niño con autismo desea ser conocido y comprendido.

Aunque la necesidad sea la misma, nuestra forma de salir a su encuentro será diferente: $L a$ manera de acceder al corazón de una persona con autismo es a través de su cuerpo (Emanuel, 2015). 
El proceso de volverse uno (sujeto, separado), normalmente tiene lugar sin que seamos conscientes de ello. En estos pequeños, sin embargo, no es así, pero tiene la oportunidad de ocurrir si lo hacemos explícito5.

\section{En contacto}

Si deseamos establecer algún contacto con un niño con un trastorno del espectro autista, hemos de ser más activos de lo normal (Rhode, 2015). Emanuel (2015) nos invita a hacer uso de la improvisación, nos informa de que tan actitud fomenta enérgicamente el compromiso emocional y de que es un gran aliado en nuestra empresa de atraer al pequeño hacia el aspecto más afectivo de la relación. A cualquiera le es más fácil jugar cuando la persona con la que está puede y sabe ser juguetona (Winnicott, 1971). Nos anima a acercarnos dispuestos a encontrar aperturas en sus experiencias, a tener la mente abierta, a estar receptivos a cualesquiera que sean los significados que puedan emerger, a cuestionarnos aquello que sabemos y a aproximarnos sabiendo que encontraremos algo. Stern (2010), por su parte, nos anima a trabajar orientados hacia una mayor libertad de la experiencia, hacia el desbloqueo de los problemas afectivos/relacionales que surgen entre el paciente y el terapeuta. Según solventamos estos, las posibilidades para la relación

\footnotetext{
5 Hace un tiempo, Ahmad y yo estábamos jugando en el suelo. Ahmad es un niño pequeño, de unos 5 años, no habla y muy rara vez emite algún sonido (salvo cuando llora). Por lo general tiene un temperamento calmado y, sin pretenderlo, tiende a dibujar muecas simpáticas en su cara. Hace unas semanas tuvimos un bonito encuentro que desde entonces somos afortunados de poder replicar de vez en cuando de manera similar. Él estaba tumbado, enfrentado a la pared con su cabeza apoyada en el suelo, yo me senté a su lado desde atrás y empecé a pasar mis dedos índice y corazón por su espalda, como si fueran los pies de una persona diminuta que iba dando pasitos sonoros ("Tic, tic, tic, tic, tic"). Después de unos "paseos", Ahmad giró un poco la cabeza, lo justo para intuirme con el rabillo del ojo y volvió a dejarla descansando sobre el suelo. Unos "paseos" más tarde, la giró algo más y volvió a su posición inicial. Poco a poco el giro fue siendo mayor y cada vez algo más sostenido. En un punto, Ahmad cambió toda su orientación corporal y se giró de forma que ya no enfrentaba la pared ni me daba la espalda, colocó su cabeza en mis talones (estaba sentada con las piernas cruzadas al estilo indio) y entonces pudimos vernos más fácilmente. Comencé a hacerle algunas cosquillas en la tripa, lo cual pareció hacerle gracia. Extendió sus manos y jugamos juntos con las suyas y las mías. Mientras le miraba desde arriba, fui haciéndole unas caricias en las distintas partes de su cara, en la barbilla, las mejillas, la nariz, ojos, cejas y frente mientras iba nombrando cada parte, haciendo pausas entre una y la siguiente, disfrutando de nuestras miradas que se encontraban, de nuestras expresiones de agrado y de estar entretenidos en el juego. Después, Ahmad cogió mis manos y las sostuvo sobre sus ojos, así que comenzamos a jugar al escondite. Unas veces iniciaba él y otras yo pero en todas las reuniones nos alegrábamos de vernos. Desde mi comprensión, creo que a lo que jugamos no fue solamente a las cosquillas, a nombrar las partes de su cuerpo y al escondite, también jugamos a descubrirnos y a encontrarnos. Creo que justamente tuvimos la oportunidad de vivir juntos un encuentro en el que hacer explícitas solo algunas de esas cosas que normalmente van permitiendo construir nuestra mismidad.
} 
analítica se expanden y según se expanden, lo hacen a su vez las posibilidades de la experiencia que pueden tener paciente y terapeuta en la presencia del otro.

Cristina describe tiernamente su interacción con Serena, una paciente con autismo, y comparte con nosotros su sensitiva y delicada comprensión de cómo, a pesar de sus propias limitaciones, Serena continuó enseñándome como alcanzar su mente (Emanuel, 2015).

\section{Encontrarnos... o no.}

Una de las cosas que sucede con frecuencia cuando estamos con un niño con autismo es que la capacidad asociativa y el proceso de pensamiento del terapeuta quedan paralizados.

María Rhode (2015) se centra en el impacto de la identificación proyectiva comunicadora ${ }^{6}$ y de la identificación adhesiva y sugiere que el grado de cohesión emocional y corporal del pequeño jugarán un factor fundamental en el desarrollo de la contratransferencia.

El pequeño hace uso de la transferencia para afectar al terapeuta -o a su proceso de pensamiento-, comunicándole así algo de su experiencia que es ciertamente incomunicable de ninguna otra manera.

Éste funcionamiento, ciertamente primitivo, podría evocar en el terapeuta la parálisis debido a que el sentido de continuidad del pequeño dependería de su adhesión a la superficie del terapeuta, por lo que cualquier movimiento (físico o psíquico) es vivido como potencialmente capaz de elicitar la desintegración. Por ello el pequeño procurará evitarlo a toda costa. Es decir, la parálisis del terapeuta estaría reflejando el miedo al movimiento (equivalente a la desintegración, a la aniquilación en la mente del pequeño). Incluso habiendo conseguido un espacio interno, si la libertad del terapeuta (psíquica \& corporal) amenazada su supervivencia, aquello que el terapeuta pone en marcha para establecer conexiones y significados, es una tremenda amenaza.

Trabajar orientados hacia el desbloqueo de los problemas relacionales que surgen en la díada terapéutica nos posibilita la expansión de la experiencia. No pretendemos tanto saber algo diferente como ser algo diferente. Tanto el paciente como el terapeuta están involucrados en la relación y en lo que se va gestando entre ellos, y aunque es cierto que es el terapeuta quien tiene que encontrar primeramente una mayor libertad hacia la experiencia, los dos participantes de la díada tendrán que convertirse en cómplices, en

\footnotetext{
${ }^{6}$ Nos unimos al uso que hace Rhode (2015) del término "identificación proyectiva evocadora" o "comunicativa". Señala el potencial comunicativo de esta y se desliga del concepto kleniano que implica la escisión de partes del self y su evacuación en el otro para poder así ser controladas.
} 
compañeros de pensamiento y de sentimiento en cada aspecto de la experiencia (Stern, 2010).

Pero estos niños no solo influyen directamente en el otro, primeramente, para contrarrestar la amenaza al sentimiento de continuidad existencial (Winnicott, 1965), se forjan sus propias sensaciones protectoras mediante estrategias confiables para ellos, como lo denominado por Bick (1968. Como se cita en Rhode, 2015) una "actividad-segunda piel" (lo que Tustin (1990) denomina "autistic shapes"7 [designa así las sensaciones autogeneradas; un ejemplo de estas pueden ser los sonidos continuos -como zumbidos-, cuando el niño da palmas o se embadurna las manos con barro $\left.{ }^{8}\right]$ ). Éstas le permiten al pequeño aprehender la ilusión de estar encapsulado por una cáscara protectora, le protegen del terror de no-ser (Tustin, 1990) (del pánico de la no-integración en términos winnicottianos), pero simultáneamente, la excesiva atención sobre las sensaciones que generan sus propios cuerpos les impide tomar conciencia de sensaciones más relevantes (por ejemplo, cuando tienen frio o el daño que se hacen cuando se caen) y utilizar los objetos/otros de un modo juguetón. Tristemente, sin juego ni sensación común de la vida, el desarrollo mental no se estimula.

\section{Impasse \& Enactment}

¿Por qué nos importa el impasse? Porque puede llegar a ser un fructífero espacio potencial. Sin embargo, es también un peligro, ya que con frecuencia, en el trabajo con estos niños, nos quedamos congelados en una posición en la que sentimos que "nada se puede hacer", y aquí colocados pasamos por alto aspectos importantes de la experiencia del niño (Rhode, 2015). Básicamente, el impasse nos importa porque antes de que podamos usarlo como un espacio provechoso y pueda tornarse, tal vez, en un enactment (que de luz a una nueva percepción del otro), nos encontramos sumidos en un lugar en el que se nos hace imposible pensar $y$, en ese estado, no hay horizonte. Para que llegue a ser beneficioso hemos de

\footnotetext{
7 Tustin (1990) entiende que los niños autistas se encuentran envueltos en sus sensaciones corporales individuales, es así como generan sus propias envolturas protectoras. Ignoran su dependencia de los otros y carecen de un sentimiento de self por lo que la autora encuentra pertinente referirse a esta "cobertura" como encapsulamiento autogenerado.

${ }^{8}$ Cuando habla de estas sensaciones autogeneradas, Tustin (1990) explica que el niño experimenta como parte de su propia superficie corporal tanto su cuerpo como los objetos externos. Ya que se experimentan como impresiones sensoriales táctiles en la superficie corporal pero no se asocian con objetos específicos, sugiere Tustin que siguiendo la senda winnicottiana, estas sensaciones podrían ser también denominadas "formas subjetivas".
} expresa. Este material es para uso científico y profesional exclusivamente y puede contener información clínica sensible. Los editores no se responsabilizan de los contenidos de los autores. Dirigir las consultas sobre derechos y autorizaciones a ceir@psicoterapiarelacional.es 
encontrar la forma de salir de la participación que estamos desempeñando en el momento del enactment y descubrir las posibilidades alternativas que no alcanzamos a articular.

El enactment es un tipo de atención extremadamente selectiva, un conjunto de percepciones del otro, y de uno mismo en relación con este otro, que son tan rígidas que no podemos imaginar ninguna otra posibilidad, al menos temporalmente (Stern, 2010).

Nos parece una posibilidad interesante plantearnos que el abordaje de la experiencia de la parálisis que venimos señalando se encuentra con frecuencia presente en el terapeuta como un enactment.

Durban (2014), sostiene que la oscilación entre la desesperación y la esperanza es un movimiento muy necesario que desempeña una función vital en el tratamiento con estos niños y que viene a luchar contra la parálisis que anida en el terapeuta (y/o en su pensamiento) creando un espacio mental tridimensional en la sesión.

\section{Comunicando}

Trabajando con estos pequeños, sentimos extremadamente y el afecto se recrudece. Con frecuencia el nivel de primitividad corporal se hace eco en la relación (Rhode, 2015) y como terapeutas tenemos que prestarnos a la interacción sabiendo que la experiencia que viven estos niños demanda de nosotros una empatía radical (Emanuel, 2015) ${ }^{9}$; nos convocan a estar con ellos como si compartiéramos un "antiguo trauma universal, una vulnerabilidad ancestral".

Rhode (2015) comenta que por lo general los niños que parecen no estar comunicando, probablemente sí que lo están haciendo. Sin embargo, debido al impacto que tienen en el terapeuta las defensas adhesivas del pequeño, el trabajo del adulto se ve entorpecido, se dificulta la toma de distancia necesaria para poder tanto reconocer como responder a la comunicación del pequeño.

Los intentos de interpretación y de realizar asociaciones significativas de lo que el pequeño comunica, tal vez una conducta o un sonido, son - por supuesto - frecuentemente fallidos, provocando en el terapeuta la sensación de que nada puede ser comunicado y la convicción de que incluso el mejor de sus esfuerzos es en vano (Rhode, 2015).

\footnotetext{
${ }^{9}$ Emanuel utiliza éste término de la forma en que Slavin (2012. Como se cita en Emanuel, 2015) lo conceptualiza. 


\section{Des-congelarnos y resonar}

Sin embargo, saldremos de la desesperación y la crudeza porque, con suerte, podremos gozar de momentos de juego significativo, porque algunos de estos niños si pueden jugar (Tustin, 1990). ¿Será que tal vez la resonancia des-congela?.

Son altamente sensibles y los encuentros que podrán ofrecernos serán probablemente efímeros, momentos increíblemente especiales, como estrellas fugaces. $Y$ no tardarán demasiado en volver a su ensimismamiento ${ }^{10}$.

Es posible que esta visión pueda ayudarnos a comprender nuestra igualmente intensa alegría y esperanza cuando sentimos conectar.

En los casos clínicos de pacientes con autismo revisados, ningún terapeuta pasa por alto la posibilidad de que parte de la comunicación del pequeño aluda a un conocimiento inconsciente de experiencias/episodios familiares (esto es, que todos otorgan significado o al menos contemplan tal posibilidad- a la enorme amalgama de peculiares comportamientos de sus pequeños pacientes). Sin desatender este aspecto (cuyo lugar en ambas mentes consideramos crucial para la paulatina emergencia de nuevos significados) comprendemos que la propuesta de trabajo no se centra tanto en desvelar significados ocultos (residentes en una mente), como en co-construir un proceso (y significados) que permita el nacimiento de una nueva comprensión (fusión de horizontes) (Stern, 2010) y experiencia.

Los terapeutas con sensibilidad resuenan con el sentimiento del pequeño cuando este consigue la hazaña: comunicar. Nuestro resonar significa que él ha sido capaz de utilizar la proyección para comunicar-nos, evocando en nosotros sentimientos o estados mentales (Rhode, 2015).

"El tirón transferencial"11, es increíblemente potente (tanto que, como señalamos, podemos llegar a quedar congelados) y en nuestra respuesta hacia él no debemos diferenciarnos de nuestra forma usual de comprender nuestro quehacer en la terapia (si en

\footnotetext{
${ }^{10}$ Hay un niño pequeño de algo menos de cinco años al cual, cuando saludo verbalmente (Hola, Saud), suelo dar también un ligero toquecito en la nariz. Ver a este niño me alegra y recibirle es para mí (creo que ahora para los dos) una alegría. Cuando espero encontrarle pero no viene me da un poquito de pena. Hace poco nos estábamos mirando y como salido de ninguna parte me dio un toquecito súper certero en la nariz y enseguida volvió a concentrarse en el trocito de madera que estaba sosteniendo. Este pequeño encuentro fue tan breve como tierno.

${ }^{11}$ Permitámonos ponerle este nombre para no enredarnos demasiado, pero sin olvidar que la transferencia no puede mantenerse sin la colaboración del otro (Stern, 2010).
} 
algo podemos diferenciarnos del resto es que nosotros no actuamos - o mejor digamos que lo hacemos de una manera "especial"12).

Los sentimientos que elicitan estos niños son a menudo aplastantes y abrumadores sospechamos que ellos los viven así: in-digeribles -. Será que el terapeuta siente tan crudamente la impotencia y el odio porque esa es la forma en que el pequeño lo siente también. Por la manera en que se nos convoca a estar con estos niños (como si compartiéramos un "antiguo trauma universal") consideramos que podría tener sentido pensar esta experiencia compartida (emocional, por largo tiempo inarticulada y cruda) como mutua influencia inconsciente (Stern, 2010).

Sin embargo, a pesar de toda la crudeza y material inmentalizable del que nos hacemos cargo trabajando con ellos, son capaces de hacer al terapeuta experimentar la "contratransferencia" a nivel corporal, lo cual nos deja cierto rastro de su capacidad de usar la identificación proyectiva (evocadora) y de la profundidad de la vivencia del pequeño del sentimiento de la frágil estructura de su mundo. La respuesta del terapeuta puede ser corporal (no solo sentirnos inmovilizados mentalmente, sino también físicamente) huella esto a su vez que podría darnos pie a sospechar la existencia de un nivel de la personalidad que es capaz de comunicar (mediante la identificación proyectiva comunicativa) y que puede permanecer separado de otro nivel en el que opera la resonancia adhesiva. Mantenerse a cierta distancia de estos niveles es importante cuando sentimos la inmovilización de nuestras asociaciones (tarea más bien difícil) (Rhode, 2015).

Como ya hemos apuntado, Rhode (2015) señala la primacía de lo primitivo y la centralidad del cuerpo cuando habla de la manera de sentir del niño en lo que respecta, entre otras cosas, a la dependencia de su supervivencia de la adhesión de sí mismo a la superficie del terapeuta. Tanto este aspecto, como su capacidad de utilizar la identificación proyectiva para despertar en el terapeuta un estado mental, son dos potentes herramientas de las que hacen uso para sobrevivir. Cuanto más profundo bucea el pequeño en el espectro, con mayor intensidad provoca la respuesta en el terapeuta, pudiendo quedarnos paralizados e incapacitados para pensar o incluso registrando sentimientos de parálisis corporal (que podrán ser el reflejo de las ansiedades corporales del niño [del peligro de "derramamiento"] y de la libertad de la que por períodos de tiempo carecemos para obtener una perspectiva).

El corazón de nuestro trabajo tiene lugar más allá de nuestra capacidad para captar los eventos que lo componen (Stern, 2010).

\footnotetext{
${ }^{12}$ Tal vez podemos decir que estamos un poco más allá de la mera repetición y que cuando ocurre hacemos algo distinto con ella. Por supuesto que fallamos, pero forma parte del proceso y la secuencia no termina ahí (en la actuación/fallo), continúa hasta una posterior reparación / re-encuentro.
} 
¿Será por eso que el resonar del terapeuta con el estado del niño es con frecuencia un momento clave en el tratamiento? Schore (2000. Como se cita en Rhode, 2015) señala la resonancia de cerebro derecho a cerebro derecho. Relacionalmente, independientemente de cómo lo denominemos, está ocurriendo algo constantemente. En la sesión somos, al menos, dos y nos afectamos mutuamente. Nuestra disposición / contención / estado emocional desde luego influyen tanto como el de la persona con la que estamos (Emanuel, 2015).

\section{Rompiendo-nos para alcanzarnos}

Puede parecer obvio, pero con frecuencia, al estar con estos niños, -no injustificadamentesomos propensos a olvidar (se nos atrofia el proceso de pensamiento) y nos rompemos la cabeza para ver qué está pasando, para intentar comprender cómo estamos juntos sin éxito alguno durante largo tiempo.

Nos sentimos derrotados, "se nos rompe el corazón" y tememos que el niño con el que estamos permanezca atascado en ese estado inalcanzable para nosotros "por el resto de su vida". Nos sentimos inútiles, incapaces de alcanzarle o de encontrar significado: "Me miraba como esperando que le trajera a la vida, deseándolo. Pero yo tenía el sentimiento de que no podía hacerlo" (Rhode, 2015).

Si normalmente el sentimiento del terapeuta nos parece el hilo guía, en estos casos lo es todavía más. Pareciera que el momento en el cual el terapeuta es capaz de "romper el hechizo inmovilizante" es con frecuencia uno de los hitos en la relación y en el tratamiento.

Si la inmovilización es una respuesta biológica ante el peligro más extremo (Fraiberg, 1982. Como se cita en Rhode, 2015 \& Tustin, 1990) tendría sentido comprender la parálisis que venimos nombrando, no solo como un enactment, también como una respuesta de protección ante una amenaza verdaderamente intensa. Tustin (1990) señala que tal inmovilización surge frente a las extremas ansiedades corporales que emergen junto a la conciencia de estar físicamente separado (la cual incluye el miedo a caer, a "desparramarse", a perder partes del cuerpo. Tal vez lo más cercano que podemos concebir a la aniquilación... algo a todas luces inmentalizable).

\section{Conclusiones}

Sumidos en tal aridez, pudiera ser que una de nuestras opciones - ya que se nos ha despojado de todas nuestras herramientas básicas (el discurso, el juego y el contacto 
emocional) (Durban, 2014) - sea prestarles nuestra mente. El significado se encarna en la relación y la relación es la mente en acción (Stern, 2010).

Cuando nos ocupamos de niños cuyo funcionamiento psíquico opera a niveles tan primitivos, la comunicación de sentimientos se confunde con la pérdida de los contenidos corporales (Rhode, 2015). Parte de nuestra función será procurar que nuestro pequeño paciente sea capaz de formar imágenes (simbolizaciones) más amplias y ricas. Habremos de proponerle y facilitarle la posibilidad de que su experiencia sea moldeada por la naturaleza de lo que ocurre entre ambos (en la relación) [invitarle a abandonar muy poco a poco la cáscara "protectora"].

El sentimiento y el pensamiento, nuestra vida mental, es posible gracias a la mentalización (que es simbolización). Tenemos la necesidad de transformar mentalmente las experiencias crudas, concretas e inmentalizables (no formuladas) y ante un paciente con deficiencias en tal proceso, procuraremos expandir la experiencia posibilitando su formulación. La representación de la experiencia simbólicamente mediada es un proceso vulnerable y continuo que puede interrumpirse por los procesos conscientes e inconscientes de la vida psíquica y relacional (Stern, 2010). Así como puede interrumpirse, confiamos también puede, en el encuentro, re-crearse.

\section{REFERENCIAS}

Durban, J. (2014). Despair and hope: on some varieties of countertransference and enactment in the psychoanalysis of ASD (autistic spectrum disorder) children. Journal of Child Psychotherapy, 40(2), 187-200.

Emanuel, C. (2015). An accidental Pokemon expert: Contemporary psychoanalysis on the autism spectrum. International Journal of Psychoanalytic Self Psychology, 10(1), 53-68.

Rhode, M. (2015). 'Paralysed associations': countertransference difficulties in recognising meaning in the treatment of children on the autistic spectrum. Journal of Child Psychotherapy, 41(3), 218-230.

Stern, D. B. (2010). Partners in thought: Working with unformulated experience, dissociation, and enactment. Routledge.

Tustin, F. (1990). The protective shell in children and adults. London: Routledge.

Winnicott, D. W. 1965. The Theory of the Parent-Infant Relationship. En The Maturational Processes and the Facilitating Environment. Londres: Karnac.

Winnicott, D. W. 1971. Playing and Reality. London: Routledge.

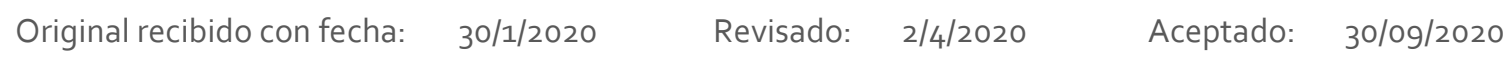

